\title{
Penile sparing therapy for penile cancer
}

\author{
Henry Han-I Yao ${ }^{1,2,3}$, Shomik Sengupta ${ }^{1,3}$, Justin Chee $^{2,4}$ \\ ${ }^{1}$ Department of Urology, Eastern Health, Melbourne, Australia; ${ }^{2}$ Department of Urology, Western Health, Melbourne, Australia; ${ }^{3}$ Eastern Health \\ Clinical School, Monash University, Melbourne, Australia; ${ }^{4}$ Department of Urology, Alfred Health, Melbourne, Australia \\ Contributions: (I) Conception and design: All authors; (II) Administrative support: S Sengupta; (III) Provision of study material or patients: J Chee; \\ (IV) Collection and assembly of data: HH Yao, J Chee; (V) Data analysis and interpretation: All authors; (VI) Manuscript writing: All authors; \\ (VII) Final approval of manuscript: All authors. \\ Correspondence to: Dr. Henry Han-I Yao. Eastern Health Clinical School, Level 2, 5 Arnold Street, Box Hill, VIC 3128, Australia. \\ Email: henryhiyao@gmail.com.
}

\begin{abstract}
Penile cancer is a rare malignancy with a reported incidence of 0.66-1.44 per 100,000 men, and a reported mortality of $0.15-0.37$ per 10,000 men. Expert clinical examination and histological diagnosis from biopsy is required to determine the extent and invasion of disease, which is paramount in planning of appropriate treatment. Management of loco-regional penile cancer can be divided into management of primary tumour and management of regional lymph nodes. This review article will focus on the management of the primary penile tumour with particular focus on penile sparing therapies. The aim of primary penile tumour management is to completely remove the tumour whilst preserving as much organ function as possible. Preservation of the penis is important as it allows patients to maintain urinary and sexual function, as well as quality of life. With the majority of penile cancer confined to the glans and foreskin, most penile cancers can be managed with organ-preserving therapy. A wide variety of treatment options are available, and this review aims to describe each of the options including the reported oncological and functional outcome for the different therapies for penile cancer.
\end{abstract}

Keywords: Penile cancer; surgery; radiotherapy; sexual function; quality of life

Submitted May 28, 2019. Accepted for publication Jul 30, 2019.

doi: $10.21037 /$ tau.2019.08.07

View this article at: http://dx.doi.org/10.21037/tau.2019.08.07

\section{Introduction}

Penile cancer is a rare malignancy with a reported incidence of $0.66-1.44$ per 100,000 men $(1,2)$, and a reported mortality of $0.15-0.37$ per 10,000 men (1). The mortality/ incidence ratios appear similar in different countries with a relatively stable incidence over time (1). The rates of penile cancer diagnosis vary between different ethnicity and increases with age $(1,2)$. The majority of penile cancer are squamous cell carcinomas (SCC), with 59\% cases diagnosed as grade I or II (2). The glans penis is the most common primary site of penile cancer $(2,3)$. A study from the Surveillance, Epidemiology and End Results Program (SEER) Public-use database revealed primary penile cancer was most commonly diagnosed as a localised stage cancer in $65.4 \%$ of cases, followed by regional stage cancer in $26.5 \%$ and distant disease in $3.5 \%$ (2). Risk factors for penile cancer included cigarette smoking, human papillomavirus (HPV) infection, phimosis, balanoposthitis, chronic inflammatory penile conditions such as lichen schlerosus, and psoralen plus ultraviolet light A treatment $(3,4)$. Neonatal circumcision is associated with a reduced risk of penile cancer which may be related to the prevention of phimosis and HPV infection (4-6). Presentation of penile cancer can vary from subtle redness on the glans to fungating lesions, and can sometimes be obscured by phimosis (3). At a minimum, expert clinical examination and histological diagnosis from biopsy is required to determine the extent and invasion of disease, which is paramount in planning of appropriate treatment (7-13). Ultrasound (US) or tumescence magnetic resonance imaging (MRI) may have a role in work-up when clinical examination is unclear, 
or there is suspicion of invasion into surrounding structures such as pubic rami or rectum (7-13). Management of locoregional penile cancer can be divided into management of primary tumour and management of regional lymph nodes. This review article will focus on the management of the primary penile tumour with particular focus on penile sparing therapies.

\section{Management of the primary penile tumour}

The goals of management for primary penile tumour are: (I) complete tumour removal, and in the case of surgery involves complete excision of tumour with negative surgical margins; (II) organ preservation as much as possible without compromising oncological outcome $(7,8)$. A large retrospective study revealed the local recurrence rate after penile-preserving therapy to be $27.7 \%$ compared with $5.3 \%$ after amputation (14). The 5 -year disease-specific survival (DSS) was reported to be $92 \%$ after a local recurrence (14), and therefore penile-preserving therapy in appropriately selected men may be justified as local recurrence has little influence on long-term survival (8). Penile preserving therapy whenever possible are now considered the primary treatment for localised penile cancer as it appears to have superior functional and cosmetic outcomes $(7,8)$. The majority of penile cancer are located on the glans or foreskin: $33.9 \%$ of lesions on glans, $15.2 \%$ of lesions on foreskin, only $3.1 \%$ on penile shaft and $2.2 \%$ overlapping lesions, with $45.6 \%$ not otherwise specified (2). With only a small proportion of tumours outside of glans and foreskin, the majority of lesions are amenable to organ-sparing surgery. However, there are no randomised controlled trials comparing any of the treatment options for localised penile cancer (8). The management options offered should be individualised to the patient taking into consideration: (I) disease factors such as clinical stage, depth of tumour invasion, grade of tumour and location of primary tumour; (II) patient factors such as length of penis, sexual function, comorbidities, compliance with follow-up and selfexamination; (III) surgeon factors such as available expertise to offer the wider array of different penile preserving therapies available. Accurate staging is paramount to the choice of management. Patients should be counselled carefully about the treatment options available (8).

\section{Tis}

Patients with carcinoma in situ (CIS) should be managed using penile-preserving therapy $(7,8)$. These include: (I) topical treatment with 5-fluorouracil (5-FU) or imiquimod; (II) laser ablation with carbon dioxide $\left(\mathrm{CO}_{2}\right)$ or neodymium: yttrium-aluminium-garnet (Nd:YAG) laser; (III) glans resurfacing $(7,8)$.

\section{Ta and T1a disease}

Similarly, patients with Ta and T1a penile cancer should also be managed with penile-preserving therapy $(7,8)$. Treatment options include: (I) laser ablation $+/-$ circumcision; (II) wide local excision $+/$ - circumcision; (III) glans resurfacing; (IV) glansectomy with reconstruction; (V) radiotherapy for lesions less than $4 \mathrm{~cm}$; (VI) Moh's micrographic surgery $(7,8)$.

\section{$T 1 b$ and $T 2$ disease}

Perform the least invasive organ-preserving surgery on patients with $\mathrm{T} 1 \mathrm{~b}$ and $\mathrm{T} 2$ disease whenever possible. Options for treatment include: (I) wide local excision +/circumcision and reconstruction; (II) glansectomy and reconstruction; (III) partial penectomy and reconstruction; (IV) total penectomy $(7,8)$.

\section{T3 disease}

T3 disease can be managed with: (I) partial penectomy and reconstruction; (II) total penectomy and perineal urethrostomy; (III) radiotherapy for lesions less than $4 \mathrm{~cm}(7,8)$.

\section{T4 disease}

The standard treatment of locally advanced penile cancer is usually with total penectomy, complete excision of tumour and perineal urethrostomy (8). For extensively locally advanced tumours, neoadjuvant chemotherapy may be utilised before surgical management in responders (8). Palliative radiotherapy can be considered in non-responders or in comorbid patients who are non-operative candidates (8).

\section{Macroscopic surgical margins}

Conventional teaching advocates for a $2 \mathrm{~cm}$ macroscopic surgical margin, which significantly limits the number of patients with penile SCC suitable for organ-sparing surgery $(15-17)$. This notion has been challenged in recent times by more contemporary series. In a series of partial and total 
penectomy, Agrawal et al. found that none of the grade 1 or 2 lesions microscopically extended beyond $10 \mathrm{~mm}$ proximal to the macroscopic margin, and none of the grade 3 lesions extended beyond $15 \mathrm{~mm}$ from the visible margin (18). Agrawal et al. recommended that a $10 \mathrm{~mm}$ margin is adequate for grade 1 or 2 penile SCC and $15 \mathrm{~mm}$ margin is adequate for grade 3 disease (18). Similarly, another series by Minhas et al. reported $48 \%$ of patients to have a microscopic margin within $10 \mathrm{~mm}$ of the tumour edge (19).

Philippou et al. found that the nearest excision margin of $5 \mathrm{~mm}$ or less versus greater than $5 \mathrm{~mm}$ was not an independent predictor of local recurrence on multivariate analysis (20). This study suggests that achieving a clear microscopic margin, even if less than $5 \mathrm{~mm}$ doesn't compromise local control (20). In this study, $6.7 \%$ of patients had positive surgical margin and all underwent further organ sparing surgery to achieve negative margins (20). With the use of intra-operative frozen section and reoperation in the event of positive margin, we can aim to be less aggressive with our margins and offer more patients penile preserving surgery as primary treatment option (20). It is therefore unnecessary to subject all patients to a $2 \mathrm{~cm}$ surgical margin. A risk adapted approach based on accurate staging can select appropriate patients for smaller margins and offer more men the option of organ sparing surgery to improve their quality of life. Furthermore, even in the event of local recurrence, the DSS does not seem to be adversely affected $(8,14,20)$. The 5 -year DSS following for patients with local recurrence is reported to be $91.7-92 \%(14,20)$. In comparison, regional recurrence is associated with much worse 5-year DSS of $32.7-38.4 \%(14,20)$. In our practice, we aim for a $5 \mathrm{~mm}$ macroscopic surgical margin in grade 1 disease, a $10 \mathrm{~mm}$ margin in grade 2 disease and a $20 \mathrm{~mm}$ margin in grade 3 disease.

\section{Functional outcome and quality of life following penile cancer treatment}

Penile cancer treatment can have significant impact on patient's quality of life in the domains of sexual function and urinary function. These can in turn impact on a patient's mental wellbeing. A small study of 30 patients showed half of the patients following treatment for penile cancer had mental symptoms on follow-up, and these patients were less satisfied and engaged in less social activity (21). The majority of patients gave priority to survival over sexual function outcome, although seven patients reported that if given the choice again they would choose treatment with higher chance of maintaining sexual potency at the expense of survival (21). Another study looking at psychosocial well-being following treatment of urological malignancies found $6 \%$ of patients to be depressed and $31 \%$ to have anxiety following treatment for SCC of penis (22). Mental wellbeing appears to be worse with increasingly mutilating surgery for treatment of penile cancer. Yu et al. reported $58 \%$ of patients to have anxiety and $39 \%$ depression following partial penectomy (23).

Sexual function decreases with increasingly mutilating and destructive surgery for penile cancer management. Total penectomy has been shown to have significant negative impact on patients' sex life and overall quality of life (24). In comparison to more destructive surgery, penile sparing interventions have a more positive impact on quality of life and sexual function (25). A study of 171 men comparing glans preserving surgery with partial amputation revealed that glans preservation results in better sexual function measured by international index of erectile function (IIEF), intercourse confidence and partner satisfaction (26). Similarly, glansectomy and urethral glanduloplasty has comparatively worse sexual function than wide local excision (27). Sedigh et al. found statistically significant decrease in IIEF and Sexual Encounter Profile (SEP) following glansectomy but not for men who underwent wide local excision (27). Given these findings, it is imperative that patients are offered the least destructive penile sparing surgery that does not compromise oncological outcome.

Following total penectomy, patients lose the ability to void whilst standing. Penile-sparing therapy preserves voiding function whilst standing but has risks of meatal stenosis and urethral stricture disease, which can negatively impact patient's urinary function (28-30). Although perineal urethrostomy following total penectomy can also be complicated with urethral stenosis and flap necrosis (31).

\section{Penile preserving surgery for penile cancer}

\section{Mob's micrographic surgery}

Moh's micrographic surgery is derived originally from dermatological practice and involves real-time histological examination of frozen section of the entire margin of excised tissue to allow mapping of remaining tumour for reexcision until a tumour-free margin is achieved $(8,32,33)$. Major draw-backs of Moh's micrographic surgery are the lack of expertise for its use in penile cancer, and lack of 
availability in many institutions.

\section{Indication}

Moh's micrographic surgery can be considered for men with CIS, Ta, T1a disease in centres with appropriate expertise in this technique (7). Accurate staging pre-operatively is important and patients should be carefully counselled regarding the possibility of alternative treatments should the defect become too large or the urethra becomes involved (32).

\section{Oncological outcome}

The first series of Moh's micrographic surgery for penile SCC was reported for patients treated between 1936 and 1986 , with a $79 \%$ cure rate at 5 years (33). Subsequently, Brown et al. reported a $5.9 \%$ recurrence rate for 17 patients with a shorter follow-up (34). Two more contemporary series have been published since then, with one study showing a 5 -year $68 \%$ recurrence free survival and the other showing $10 \%$ and $12 \%$ recurrence rate for CIS and invasive SCC, respectively $(32,35)$. Recurrence is most commonly treated with repeated Mohs micrographic surgery with good outcomes. The 5 -year cancer-specific survival (CSS) is $96 \%$ and 5 -year overall survival (OS) is $92 \%$ in a contemporary series (32).

\section{Complications and functional outcome}

Two of the studies reported meatal stenosis and urethral stricture to be an issue post-operatively for patients with urethral involvement of SCC or CIS $(32,35)$. Wound dehiscence has also been reported following Moh's micrographic surgery (32). None of the studies reported sexual function outcome post-operatively.

\section{Circumcision and Wide Local Excision}

\section{Indication}

Penile lesions confined to the foreskin accounts for $15.2 \%$ of primary penile cancer in a large SEER database (2). Patients with CIS and superficial disease (Ta, T1) confined to the foreskin can be managed safely with radical circumcision (36). Similarly, CIS and superficial disease involving the glans and penile shaft skin can be treated with wide local excision (Figure 1), and the defect closed with primary closure, skin flap or split thickness skin graft $(36,37)$.

\section{Oncological outcome}

One study of radical circumcision and wide local excision for patients with CIS, Ta, T1 and T2 penile cancer showed a local control rate of $90.6 \%$ with a relative short median follow-up of 26.5 months (36). In this study, the three patients who died from metastatic disease all had positive lymph nodes (36). The author aimed for at least $5 \mathrm{~mm}$ margins and reported no positive margins on both frozen sections and final histopathology (36).

\section{Complications and functional outcome}

Similar to standard penile skin lesion excision and circumcision, there are risks of wound dehiscence and infection. One study reported a $9.4 \%$ rate of wound complications (36). In regards to sexual function, Li et al. evaluated 29 patients following circumcision and/or wide local excision, and found 21 out of the 22 patients with none or mild erectile dysfunction reported the same level of sexual function post-operatively (36). The same study also reported all patients to be satisfied with urination in the post-operative survey (36).

\section{Laser ablation}

\section{Indication}

Laser ablation of penile lesion is a minimally invasive treatment option for the management of penile CIS, Ta and T1a penile SCC $(7,8)$. Laser energy source used in the treatment of penile cancer includes $\mathrm{CO}_{2}$ and Nd:YAG (38), or a combination of both (39).

\section{Operative technique}

Operative technique for various laser treatments for penile carcinoma can be found elsewhere (38-42). In brief, $\mathrm{CO}_{2}$ laser can be used to excise the lesion with adequate surgical margins followed by adjunctive peripheral vaporisation of the wound (40). Local application of $5 \%$ acetic acid for 20 minutes can be used to map lesions prior to laser coagulation with $\mathrm{Nd}$ :YAG laser in a continuous wave mode at $30-50 \mathrm{~W}$ in air $(41,42)$. A combination method of excising macroscopic lesions using $\mathrm{CO} 2$ laser followed by coagulation of tumour bed with Nd:YAG laser has also been described (39).

\section{Oncological outcome}

The local recurrence rate is high following laser therapy for penile carcinoma (8), with reported rates ranging from $10 \%$ to $48 \%$ for Nd:YAG laser $(8,41,42), 14 \%$ to $23 \%$ for $\mathrm{CO}_{2}$ laser $(40,43,44)$ and $19 \%$ for combined $\mathrm{CO}_{2}$ and $\mathrm{Nd}$ :YAG laser technique (39). 

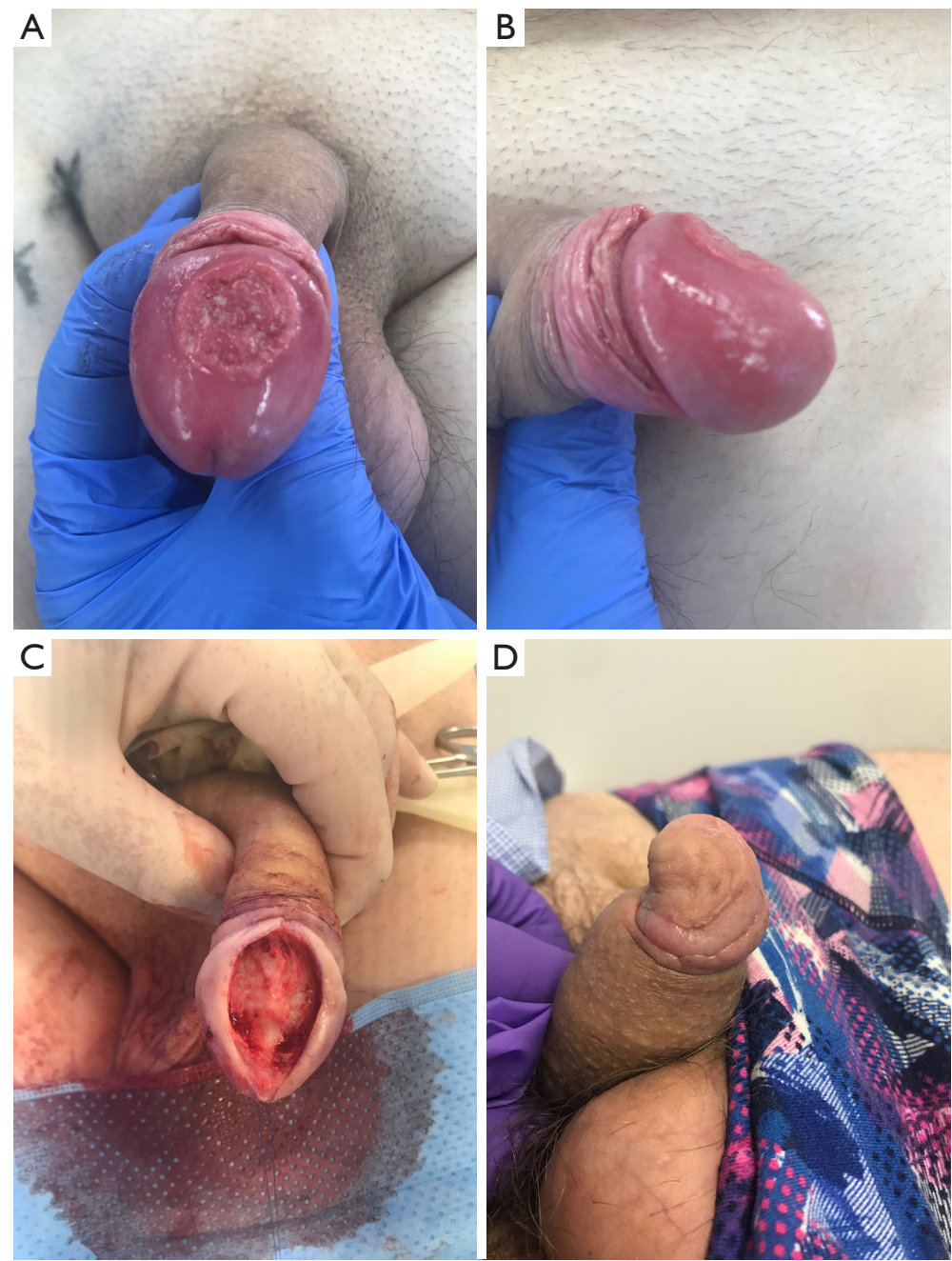

Figure 1 Wide local excision of penile SCC confined to the glans penis. (A) Top down view of the penile SCC pre-operatively; (B) side view of the penile SCC pre-operatively; (C) wide local excision defect which was subsequently covered with split thickness skin graft; (D) postoperative appearance after healing. SCC, squamous cell carcinoma.

\section{Complications and functional outcome}

Laser therapy for penile cancer can achieve satisfactory cosmetic result and erectile function (39). Windahl et al. reported that $78 \%$ of men were satisfied with the cosmetic result and $72 \%$ of men had unaltered erectile function postoperatively (39). In the series by Bandieramonte et al., none of the men complained of any changes in erectile function or functional impairment for sexual activity (40). Urinary function was generally well-preserved following operation with a very low risk of meatal stenosis $(39,40)$.

Reported rates of complications were generally low and included bleeding, infection, with less than $1 \%$ risk of meatal stenosis $(8,39,40)$. However, the healing process following laser therapy can take up to $8-10$ weeks (39).

\section{Glans resurfacing}

Glans resurfacing is a surgical technique that involves the removal of the epithelial and subepithelial layer of the glans, followed by covering the defect with a split thickness skin graft (45). This was first described by Depasquale et al. for the treatment of severe lichen sclerosus of glans penis $(46,47)$. Several case series have been reported for the use of glans resurfacing in penile pre-malignant and malignant lesions $(45,46,48-50)$. 

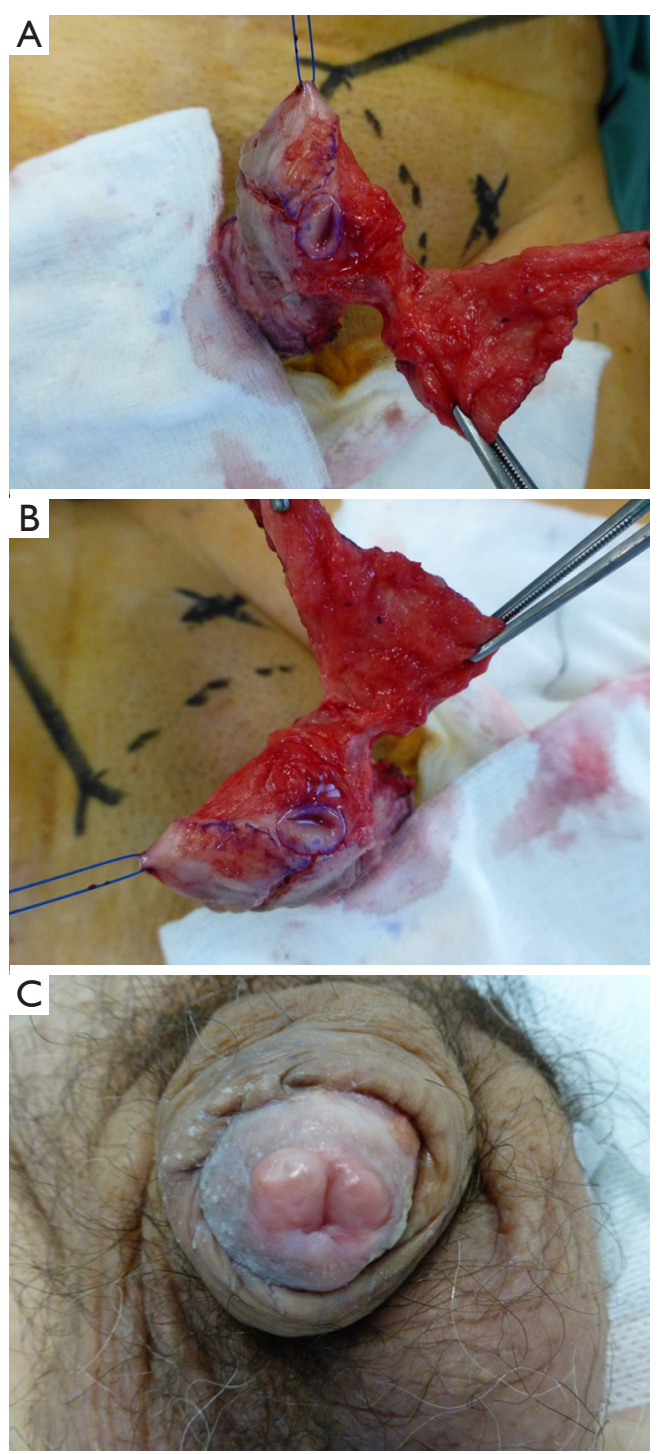

Figure 2 Glans resurfacing as treatment for penile cancer. (A,B) Intra-operative photos of glans resurfacing demonstrating the removal of epithelial and subepithelial layer in each quadrant sparing the meatus; (C) post-operative photo of glans resurfacing after healing.

\section{Indication}

Glans resurfacing can be considered as a surgical treatment option for CIS and superficial penile cancer (Ta, T1a) confined to the glans penis (8).

\section{Operative technique}

Patient is placed under general anesthesia in a supine position and given pre-operative antibiotics $(45,46)$. A tourniquet is placed on the base of the penis and the glans is marked out in quadrants using blue ink from meatus to coronal sulcus $(45,46)$. Using sharp dissection, a plane is developed between the subepithelial layer of glans and corpus spongiosum to facilitate complete removal of epithelial and subepithelial layer in each quadrant sparing the meatus (Figure 2) $(45,46)$. We also take small biopsies of the underlying defect to ensure clearance of tumour. To cover the defect, a split thickness skin graft is harvested from the thigh using a dermatome $(45,46)$. The skin graft is fenestrated, quilted and sutured in place using 5/0 Vicryl Rapide $^{\mathrm{TM}}$ (Ethicon, Johnson \& Johnson, USA) from the meatus distally to the corona proximally $(45,46)$. Tourniquet is released and Xeroform ${ }^{\mathrm{TM}}$ (Covidien, Medtronic, USA) dressing is placed over the graft and secured in place using $\operatorname{Coban}^{\mathrm{TM}}$ (3M, USA) dressing. The dressing is removed after three days and re-dressed before removing completely on day 7 post-operatively along with the $16 \mathrm{Fr}$ urethral catheter placed at the end of the operation. Chlorsig ${ }^{\circledR}$ ointment (Aspen Pharma, South Africa) is applied to the graft twice daily for two weeks followed by daily Vaseline ${ }^{\circledR}$ (Unilever) to the neoglans surface. Skin donor site is dressed with Jelonet ${ }^{\circledR}$ (Smith \& Nephew, UK), Tegederm ${ }^{\text {TM }}$ absorbent (3M, USA) and Mefix ${ }^{\circledR}$ (Molnlycke, Sweden) for 7-10 days. Patients are advised to avoid sexual activity for six weeks.

\section{Oncological outcome}

The five studies included in this review have a mean followup of 19.6 to 32 months $(45,46,48-50)$. The range of pathology treated included pre-malignant conditions, CIS, $\mathrm{Ta}, \mathrm{T} 1$ and $\mathrm{T} 2$ disease. The positive margin rate of total glans resurfacing ranged from $0 \%$ to $20 \%(45,46,48)$. For partial glans resurfacing, the positive margin rate is reported to be as high as $67 \%(48)$. The rate for further surgical intervention ranged from $2.5-17.6 \%(45,46,48-50)$. With a short follow-up, current data suggests a low recurrence rate of $0-5 \%$ and minimal risk of progression with $0 \%$ in all reported series $(45,46,48-50)$.

\section{Complications and functional outcome}

Sexual function was reported in 3 studies and all patients who were sexually active pre-operatively were still active post-operatively $(45,46,50)$. O'Kelly et al. reported that $81 \%$ of patients had normal glans sensation post-operatively (45). Three studies reported specifically no meatal stenosis $(45,46,49)$, the remaining 2 studies did not report on urinary function post-operatively. 
None of the studies reported any intra-operative complications $(45,46,48-50)$. Graft breakdown occurred in $4 \%$ to $11.8 \%$ of cases, with no other significant postoperative complications $(45,46,48-50)$.

\section{Glansectomy}

\section{Indication}

Early stage penile cancer such as Ta, T1 and T2 disease involving the glans only can be managed with glansectomy primarily or as a salvage treatment following local recurrence after penile-sparing therapy such as radiotherapy $(8,51)$. Other indications include for benign conditions such as severe destruction of glans secondary to radiotherapy, inflammatory penile conditions (e.g., pyoderma gangrenosum), and iatrogenic trauma (e.g., during circumcision) (51).

\section{Operative technique}

Under general anesthesia in a supine position, preoperative antibiotic is given and a penile nerve block is instilled (51). A tourniquet is placed around the base of the penis, and a subcoronal incision is extended down to Buck's fascia (51). Sharp dissection with scissors is used to dissect the glans cap from the corporal bodies circumferentially (51). The dorsal neurovascular bundle is identified, divided and oversewn at this level (51). The urethra is then transected at the level of the corporal head (51). Penile skin is sutured to the corporal body leaving the tip exposed to function as pseudo-glans (51). A split thickness skin graft of adequate size to cover the defect left by the glansectomy is harvested from the thigh with a dermatome (51). The donor site is dressed as per previous description. The skin graft is fenestrated, placed over the neo-glans, quilted and sutured to the meatus and penile skin using 5/0 Vicryl Rapide ${ }^{\mathrm{TM}}$ (Ethicon, Johnson \& Johnson) sutures. The remainder of the operation and follow-up is similar to the description above for glans resurfacing.

\section{Oncological outcome}

The local recurrence rate is low following glansectomy. In a study of 117 patients the local recurrence rate was $12.8 \%$ after a median follow-up of 33.7 months (52). This study found perineural invasion, CIS, positive margin and highgrade disease to be risk factors for local recurrence (52). Similarly, another study of 177 patients with penile SCC reported a local recurrence rate of $9.3 \%(n=16 / 172)$ and cancer-specific death of $10.3 \%(\mathrm{n}=18 / 174)$ after a median follow-up of 41.4 months (29). Two other smaller studies of 39 and 25 patients showed only one local recurrence after a mean follow-up of 16 and 28 months, respectively $(53,54)$. The reported DSS of $92 \%$ was similar to larger studies (54).

\section{Complications and functional outcome}

Complications reported are usually related to the reconstruction. One study reported partial and complete graft loss in $20 \%$ and $3.4 \%$ of cases, respectively (29). Radionecrosis of glans requiring debridement is a much less frequent complication (53).

Sexual function is well preserved following glansectomy. A study of 39 patients found coital ability post-operatively in $84 \%$ of patients and orgasm feeling maintained in $78 \%$ of patients (55). Another study of 11 patients who had sexual function evaluation following glansectomy found 9 patients to be able to achieve erections and 6 patients to be sexually active (54). A mixed study of mostly glansectomy patients with some distal corporectomy patients revealed all 22 patients who had good erections pre-operatively, maintained the same rigidity after surgery (56). About $74 \%$ of patients in this study resumed sexual activity after the surgery (56). Ventral chordee was noted in 2 patients $(9 \%)$ in this study (56). Although urinary outcome was not specifically reported, $2.8-8 \%$ of patients developed meatal stenosis requiring dilation or meatoplasty $(29,54)$. Penile hematoma has been reported in up to $6 \%$ of patients and may even require surgical evacuation (56).

\section{Partial penectomy}

\section{Indication}

Depending on the degree of partial penectomy, the organ preserving nature of this treatment is debatable. The benefit of partial penectomy over total penectomy is the preservation of a penile stump which may allow a degree of sexual function and voiding from standing position. Partial penectomy can be used to treat $\mathrm{T} 2$ or $\mathrm{T} 3$ disease involving the shaft of the penis.

\section{Operative technique}

Patient is placed under general anesthesia in a supine position with prophylactic antibiotics given (57). Tourniquet is placed around the base of penis and marking is made circumferentially to aim for adequate surgical margin (57). A surgical glove is placed around the penile cancer to 

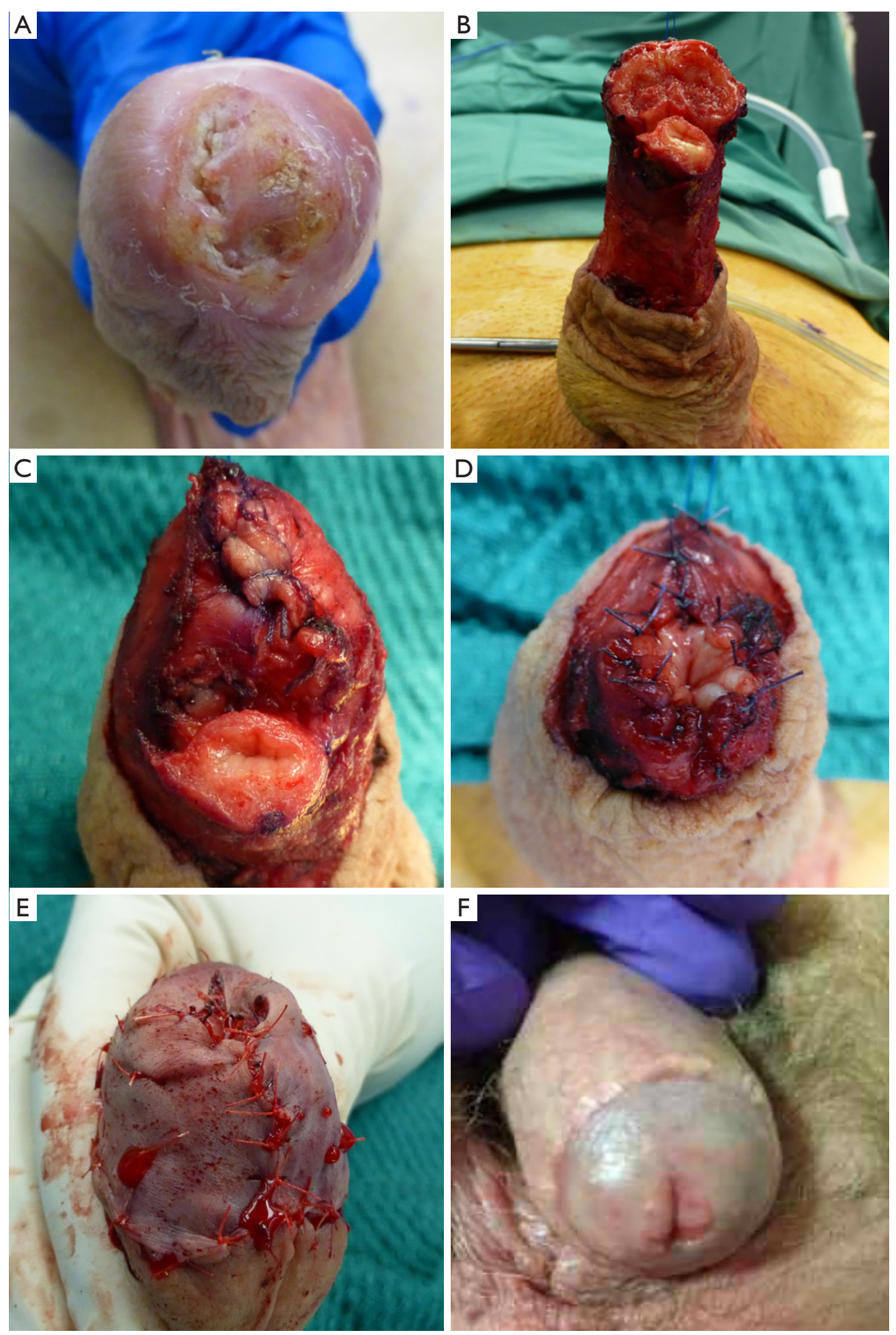

Figure 3 Partial penectomy and split thickness skin graft reconstruction for penile SCC. (A) Penile SCC involving the glans and urethral meatus; (B) intra-operative photo after partial penectomy was performed; (C) closure of the corpus cavernosum; (D) suturing of the neomeatus to corpus cavernosum; (E) corpus cavernosum covered with split thickness skin graft; (F) post-operative appearance after wound healed. SCC, squamous cell carcinomas. 
avoid contamination and spillage of tumour cells (57). Circumferential incision is made at the marked line down to tunica albuginea of the corporal bodies (Figure 3) (57). The neurovascular bundle in the dorsal midline is mobilised off the corporal bodies and ligated (57). The urethra is mobilised off the corporal bodies approximately $2.5 \mathrm{~cm}$ distal to the marked margin, spatulated and everted to cover the corporal head if the urethra is not involved by tumour (56). The corporal stumps are closed in a running fashion with $3 / 0$ braided absorbable sutures (57). The urethral edges are sutured to the underlying corporal tips to form a neo-glans (56). The penile skin is then sutured to the edge of the neoglans and neo-meatus using 5/0 Vicryl Rapide ${ }^{\mathrm{TM}}$ (Ethicon, Johnson \& Johnson) sutures. If the urethra is involved with tumour, the penile skin can be mobilised to recreate the neoglans and sutured to the spatulated neo-meatus (57). A light compressive dressing is placed and a $16 \mathrm{fr}$ urethral catheter is left in situ for 24-48 h $(56,57)$.

\section{Oncological outcome}

The local recurrence rate is low following partial penectomy. In a study of 32 patients with penile cancer treated with partial penectomy and a median follow-up of 38 months, there was only one local recurrence that occurred 4 months post-operatively, and subsequently managed with total penectomy (58). Two patients in this study had positive surgical margins, one patient proceeded to total penectomy and the other was managed with systemic chemotherapy due to nodal disease (58). The OS at 3 years was poor at $56 \%$, which is more reflective of the high rates of nodal disease in this cohort as only one patient had local recurrence (58), $78 \%$ and $69 \%$ of patients in this study underwent inguinal and pelvic lymph node dissection, respectively (58). One patient had positive pelvic lymph node and 15 patients had positive inguinal lymph node for metastases (58).

Two larger series of 96 patients and 194 patients also report similarly low local recurrence rates following partial penectomy for penile SCC (30,59). The first study showed that none of the patients with $\mathrm{T} 1(\mathrm{n}=0 / 4)$ disease developed local recurrence, and $11 \%(\mathrm{n}=10 / 92)$ with $\mathrm{T} 2$ disease developed local recurrence (30). They also showed the $88 \%$ 5 -year local recurrence free survival for penis amputation surgery (96/100 partial penectomy) was superior to the $63 \%$ for patients who underwent penile preservation therapy (30). Rate of local recurrence following partial penectomy was not separately reported in the second study, although they reported only 6 local recurrences and 10 simultaneous local and regional recurrences for the entire cohort of 333 patients treated with circumcision, local excision, partial penectomy and total penectomy (59). The disease-free survival for the 194 patients who underwent partial penectomy was $74 \%$ after a mean follow-up of 100 months (59).

Two other smaller studies of 18 and 23 patients who had partial penectomy for penile SCC also showed similar findings $(60,61)$. The first study of 18 patients showed no local recurrence during the study period spanning 10 years (60). The second study of 23 patients reported a local recurrence rate of $13 \%(\mathrm{n}=3)$ after a median follow-up of 14 months (61). This was significantly lower compared with primary radiotherapy in the same study which had a local recurrence rate of $58 \%(n=19 / 33)(61)$. However, there was no difference in the 10-year CSS for patients treated with radiotherapy versus surgery (61). This further highlight that survival is less dependent on local recurrence but more on other factors such as grade of disease, nodal and distant metastases. The 10-year CSS in this study was $53 \%$ for patients treated with surgery (23 partial penectomy and 4 penectomy) (61).

\section{Complications and functional outcome}

Sexual function following partial penectomy appears to be worse in comparison to less destructive surgeries. A study of 43 patients following partial penectomy revealed significantly lower IIEF post-operatively compared with pre-operative scores (23). Only $48.8 \%$ of patients reported erectile function that is "most times" or "always" adequate for sexual intercourse (23). In regard to orgasmic function, $65.1 \%$ of men reported to achieve ejaculation or feeling of orgasm "most times" or "always (23). Sexual intercourse was satisfactory "most times" or "always" in $37.2 \%$ of patients (23). Only $16.3 \%$ of patients were "very or moderately satisfied" with their overall sexual function (23). Sexual function appears to be worse in older men and those with anxiety, and better in men with longer penile length pre-operatively (23).

Another study of 28 patients with at least 6 months follow-up found 6 patients to have decreased erectile function, one patient to have decreased libido and one patient to have decreased force of urinary stream (58). In another study, urethral stenosis following partial penectomy have been reported to be as high as $8.3 \%$ (30). Other complications from partial penectomy can be related to wound and flap complications. 


\section{Non-surgical organ preserving therapy for penile cancer}

\section{Topical therapy}

\section{Indication and mechanism of action}

An alternative to surgery for treatment of penile CIS is topical therapy (8). The two topical therapies used for this indication are 5-FU and imquimod (8). 5-FU exerts its anti-tumour effects via impairing the normal synthesis and functioning of RNA and DNA (62). Tumour cells are affected more than normal cells due to the increased uptake of 5 -FU in rapidly dividing cells (63). The mechanism of action of imiquimod is primarily based on activating the innate immune system (64). Imiquimod stimulates antigen presenting cells to promote a $\mathrm{T}$ cell response (64). It also stimulates toll-like receptors (TLRs) which leads to downstream signalling resulting in elevation of many gene products that are involved in regulation of the innate immune system including cytotoxic T cells (64).

\section{Regimen}

A course of 5-FU is usually 3 weeks and it is applied twice daily to affected area and left on until absorbed (65). Significant localised inflammation is treated with $0.5 \%$ hydrocortisone cream applied to affected area twice daily (65). Treatment regimen for imiquimod varies widely in the literature (66). Some studies involved patients applying imiquimod to the affected area less than four times per week, whilst others applied it at least four times per week (66). The duration of therapy also varied widely, although most involved 16 weeks or less in duration (66).

\section{Oncological outcome}

Overall, the results of topical therapy show that it is only moderately effective with a limited complete response rate and a similar recurrence rate to organ preserving surgical treatment in the short-term. A study reporting the outcome of 44 patients with penile CIS treated with 5 -FU showed a complete response rate of $50 \%$ after $1-3$ courses of treatment (67). Failed 5-FU treatment was followed by second-line imiquimod in nine patients resulting in an overall complete response rate of $57 \%$ (67). After a median follow-up of 34 months, the recurrence rate was $20 \%$ with a mean time to recurrence of 5 months (67). Another study looking at treatment outcome of 5-FU for glans CIS routinely circumcised all patients to prevent inflammation and adhesion of foreskin as a result of 5-FU (65). Lucky et al. reported a $73.7 \%$ complete response rate with no recurrence after a mean follow-up of 3.5 years (65). A systematic review of the literature reported the complete response rate of imiquimod for penile intraepithelial neoplasia to be $63 \%$ $(n=48)$, and a recurrence of $4 \%$ during follow-up (66).

\section{Complications and functional outcome}

Local toxicity was reported in $10 \%$ of patients and adverse events reported in $12 \%$ of patients in one study (67). Significant inflammation can result following 5-FU treatment and is reported in $36.8 \%$ in one study, which included one patient who was admitted for pain control and one patient who developed neo-phimosis (65). Toxicity following imiquimod is extrapolated from extragenital disease (63). The most common toxicity is local inflammatory reaction, and other side effects include flulike symptoms, myalgia and headache (63).

None of the studies specifically reported on urinary or sexual function following topical therapy. With complete preservation of penis, it is most likely that urinary and sexual function is largely preserved.

\section{Radiotherapy}

\section{Indication}

Radiotherapy offers another penile sparing option for the management of penile SCC. Radiotherapy can be offered as a treatment option of Ta to T3 penile SCC that are less than $4 \mathrm{~cm}$ in size (8). The two forms of radiotherapy for penile cancer are external beam radiotherapy (ERBT) and interstitial brachytherapy (68). Although radiotherapy can achieve a reasonable local control, the main disadvantages are: (I) lack of accurate staging from excised histopathology; (II) need for circumcision to prevent paraphimosis; (III) risk of necrosis; (IV) risk of meatal stenosis or urethral stricture disease; (V) fibrosis and disfiguration of penis which can also have an impact on surveillance (69). As such, radiotherapy is infrequently used for treatment of penile cancer as demonstrated from the SEER database, which showed EBRT used as standalone treatment in only $2.2 \%$ of patients (70).

\section{Oncological outcome}

\section{Brachytherapy}

Brachytherapy appears to achieve a moderately effective result in local control and penile preservation. The local recurrence free rate at 5 years ranged from $74-87.3 \%$ 
and the penile preservation rate were reported to be $66-86 \%(28,68,71-73)$. DSS at 5 years ranged from 85-91.4\% (28,68,71-73). Crook et al. reported a series of 67 patients who underwent continuous low dose rate (LDR) brachytherapy for T1-T3 penile SCC (68). They treated tumours up to $5 \mathrm{~cm}$ in size, although $62 \%$ were less than $3 \mathrm{~cm}$ in size (68). The prescribed dose was $60 \mathrm{~Gy}$ given over 4-5 days (68). Local recurrence free survival was reported to be $87.3 \%$ at 5 years and $72.3 \%$ at 10 years (68). Of the 8 patients who had recurrences, they all underwent salvage partial or total penectomy (68). The OS at 10 years was reported to be $59 \%$ and CSS was $83.6 \%$ (68). Another series reported by Cordoba et al. included 73 patients treated with a median dose of 60 Gy LDR brachytherapy for CIS and T1-T2 penile SCC (72). The reported 5-year OS, CSS, local recurrence-free survival were $82 \%, 91.4 \%$ and $74 \%$, respectively (72,74). de Crevoisier et al. reported similar outcomes for LDR brachytherapy in 144 patients with penile SCC confined to the glans (75). The median tumour size was $20 \mathrm{~mm}$ (range, $2-50 \mathrm{~mm}$ ) (75). The 10-year local recurrence rate was $20 \%$, and the 10 -year CSS was $92 \%$. Another study of 47 patients with penile cancer treated with primary brachytherapy revealed a penis preservation rate of $66 \%$ and a 5 -year DSS and disease-free survival of $87.6 \%$ and $84 \%$, respectively $(73)$.

\section{ERBT}

ERBT appears to be less effective than brachytherapy in the treatment of penile SCC based on reported numbers and not head-to-head comparison. The local recurrence free survival at 5 years ranged from $37-62 \%$, and CSS at 5 years were $66-96 \%(28,60,68,71,74)$. The 5-year penile preservation rates were $36-88 \%(28,60,68,71,74)$, which dropped down to $18-67.3 \%$ at 10 years $(68,71)$. Gotsadze et al. reported a series of 155 penile SCC patients given 40-60 Gy of ERBT, and after a median follow-up of 78 months they reported a local control rate of $65 \%$ and a DSS of $82 \%$ at 10 years $(69,76)$. Mistry et al. reported the outcome of 18 patients who underwent primary ERBT for treatment of penile cancer using 50-55 Gy in 16-20 fractions (60). Eight of eighteen patients (44.4\%) relapsed following radiotherapy and subsequently underwent salvage total or partial penectomy (60). The actuarial recurrence rate after radiotherapy was reported to be $37 \%$ at 5 years (60). In a study of mostly EBRT (18 ERBT alone, 4 EBRT + brachytherapy boost, 1 brachytherapy alone) with a dose of 45-74 Gy given in 1.8-2 Gy/fraction, and a median follow-up of 70 months, the local recurrence rate was $61 \%$ compared with $25 \%(n=4 / 16)$ for patients treated with partial penectomy $+/-$ post-operative radiotherapy (71). $83 \%$ of the local failures following radiotherapy was successfully salvaged with surgery (71). The 5 year OS rate was $62 \%$, and the 5 -year and 10-year probabilities of surviving with intact penis were $36 \%$ and $18 \%$, respectively (71). Similarly, Ozsahin et al. reported a $56 \%$ local recurrence rate for patients treated with primary radiotherapy for penile SCC (21 ERBT alone, 7 ERBT and brachytherapy, 1 brachytherapy alone) (61). The 10 -year CSS was $56 \%$ which was not different to the survival of partial or total penectomy in the same study (61). The 5-year probability of surviving with an intact penis was $43 \%$ and 10 -year probability was 26\% (61). Another study of 41 patients treated with ERBT of 50-52.5 Gy in 16 fractions and a median follow-up of 4.5 years, reported a local control rate of $62 \%$ and OS of $88 \%$ at 5 years (28).

\section{Complications and functional outcome}

Urethral stenosis and penile necrosis are the two main complications following radiotherapy for penile SCC. Rates of penile necrosis ranged from $2-23 \%$, and rates of urethral stenosis ranged from $12-45 \%$ in the literature $(28,77)$. Other reported complications from radiotherapy included skin changes, oedema, phimosis, complete glans deformation and sexual dysfunction (30,71).

In a study that included 29 patients with penile SCC treated with radiotherapy, 2 patients were found to have urethral stenosis (30). One of these patients subsequently had partial penectomy due to the severity of the meatal stenosis (30). Another study of 29 patients who underwent either brachytherapy and/or ERBT reported a $10 \%$ rate of urethral stenosis after treatment which were successfully treated with urethral dilation (61). Zouhair et al. reported $9 \%(\mathrm{n}=2 / 23)$ of patients treated with primary radiation therapy to have developed urethral stenosis post-radiation, all of which were treated successfully with dilatation (71). Penile necrosis is another significant complication following penile cancer radiotherapy, and in a study of 259 patients the rate was reported to be $6.2 \%$ and similar for both brachytherapy and EBRT (78). All patients with penile necrosis were treated with partial or total penectomy in this study (78). In another study of 18 patients who had EBRT for penile cancer, two patients developed necrosis, one developed phimosis, one had erectile dysfunction and one had urethral stricture following the treatment (60). 
Unfortunately, most studies of brachytherapy and ERBT for penile cancer have a poor follow-up of late toxicity such as sexual dysfunction (28). A couple of small studies have reported specifically on sexual function outcome, and sexual function appears to be reasonably preserved for patients who have had successful penis preservation following radiotherapy for penile cancer $(73,79)$. In a small study, $58.8 \%(\mathrm{n}=10 / 17)$ of sexually active patients remained sexually active following brachytherapy, and $94.4 \%(\mathrm{n}=17 / 18)$ maintained erections after primary brachytherapy for penile cancer (73). Another study reported 10 out of 12 patients treated with definitive radiotherapy for penile cancer had the same or slightly reduced sexual global function (79).

\section{Conclusions}

The aim of primary penile tumour management is to completely remove the tumour whilst preserving as much organ function as possible. With the majority of penile cancer confined to the glans and foreskin, most penile cancers can be managed with organ-preserving therapy. A wide variety of treatment options are available. Treatment should be individualised and is based on accurate preoperative staging as well as other patient, disease and surgeon factors. Intra-operative frozen section and repeat therapy in the event of positive margin should be used to achieve negative margins. Local control is moderately effective for most penile-preserving therapy. Local recurrence has a low impact on DSS and can be managed with another organ-preserving therapy in some cases. Compliance with close surveillance including frequent self-examination and clinician examination is paramount to detect local recurrence early, as timely treatment before spread to nodal and distant disease is important. Preservation of the penis is important as it allows patient to maintain urinary and sexual function, improve their quality of life and mental well-being.

\section{Acknowledgments}

Funding: None.

\section{Footnote}

Provenance and Peer Review: This article was commissioned by the editorial office, Translational Andrology and Urology for the series "Surgery for Urologic Cancers". The article has undergone external peer review.
Conflicts of Interest: All authors have completed the ICMJE uniform disclosure form (available at http://dx.doi. org/10.21037/tau.2019.08.07). The series "Surgery for Urologic Cancers" was commissioned by the editorial office without any funding or sponsorship. SS served as the unpaid Guest Editor of the series and serves as an unpaid editorial board member of Translational Andrology and Urology from Jul 2018 to Jun 2020. The authors have no other conflicts of interest to declare.

Ethical Statement: The authors are accountable for all aspects of the work in ensuring that questions related to the accuracy or integrity of any part of the work are appropriately investigated and resolved.

Open Access Statement: This is an Open Access article distributed in accordance with the Creative Commons Attribution-NonCommercial-NoDerivs 4.0 International License (CC BY-NC-ND 4.0), which permits the noncommercial replication and distribution of the article with the strict proviso that no changes or edits are made and the original work is properly cited (including links to both the formal publication through the relevant DOI and the license). See: https://creativecommons.org/licenses/by-nc-nd/4.0/.

\section{References}

1. Sewell J, Ranasinghe W, De Silva D, et al. Trends in penile cancer: a comparative study between Australia, England and Wales, and the US. Springerplus 2015;4:420.

2. Barnholtz-Sloan JS, Maldonado JL, Pow-sang J, et al. Incidence trends in primary malignant penile cancer. Urol Oncol 2007;25:361-7.

3. Pow-Sang MR, Ferreira U, Pow-Sang JM, et al. Epidemiology and natural history of penile cancer. Urology 2010;76:S2-6.

4. Minhas S, Manseck A, Watya S, et al. Penile cancer-prevention and premalignant conditions. Urology 2010;76:S24-35.

5. Daling JR, Madeleine MM, Johnson LG, et al. Penile cancer: importance of circumci-sion, human papillomavirus and smoking in in situ and invasive disease. Int $\mathrm{J}$ Cancer 2005;116:606-16.

6. Schoen EJ, Oehrli M, Colby C, et al. The highly protective effect of newborn cir-cumcision against invasive penile cancer. Pediatrics 2000;105:E36.

7. Flaig TW, Spiess PE, Agrawal N, et al. NCCN Clinical Practice Guidelines in Oncology - Penile Cancer. 2018. 
Accessed 20 April 2019. Available online: https://www. nccn.org/professionals/physician_gls/pdf/penile.pdf

8. EAU Guidelines on Penile Cancer. 2019. Accessed 20 April 2019. Available online: https://uroweb.org/guideline/ penile-cancer/

9. Bozzini G, Provenzano M, Romero Otero J, et al. Role of Penile Doppler US in the Preoperative Assessment of Penile Squamous Cell Carcinoma Patients: Results From a Large Prospective Multicenter European Study. Urology 2016;90:131-5.

10. Hanchanale V, Yeo L, Subedi N, et al. The accuracy of magnetic resonance imaging (MRI) in predicting the invasion of the tunica albuginea and the urethra during the primary staging of penile cancer. BJU Int 2016;117:439-43.

11. Kayes O, Minhas S, Allen C, et al. The role of magnetic resonance imaging in the local staging of penile cancer. Eur Urol 2007;51:1313-8; discussion 1318-9.

12. Lont AP, Besnard AP, Gallee MP, et al. A comparison of physical examination and imaging in determining the extent of primary penile carcinoma. BJU Int 2003;91:493-5.

13. Scardino E, Villa G, Bonomo G, et al. Magnetic resonance imaging combined with artificial erection for local staging of penile cancer. Urology 2004;63:1158-62.

14. Leijte JA, Kirrander P, Antonini N, et al. Recurrence patterns of squamous cell car-cinoma of the penis: recommendations for follow-up based on a two-centre analysis of 700 patients. Eur Urol 2008;54:161-8.

15. Hardner GJ, Bhanalaph T, Murphy GP, et al. Carcinoma of the penis: analysis of therapy in 100 consecutive cases. J Urol 1972;108:428-30.

16. Narayana AS, Olney LE, Loening SA, et al. Carcinoma of the penis: analysis of 219 cases. Cancer 1982;49:2185-91.

17. Veeratterapillay R, Sahadevan K, Aluru P, et al. Organpreserving surgery for penile cancer: description of techniques and surgical outcomes. BJU Int 2012;110:1792-5.

18. Agrawal A, Pai D, Ananthakrishnan N, et al. The histological extent of the local spread of carcinoma of the penis and its therapeutic implications. BJU Int 2000;85:299-301.

19. Minhas S, Kayes O, Hegarty P, et al. What surgical resection margins are required to achieve oncological control in men with primary penile cancer? BJU Int 2005;96:1040-3.

20. Philippou P, Shabbir M, Malone P, et al. Conservative surgery for squamous cell carcinoma of the penis: resection margins and long-term oncological control. J Urol 2012;188:803-8.

21. Opjordsmoen S, Fossa SD. Quality of life in patients treated for penile cancer. A follow-up study. Br J Urol 1994;74:652-7.

22. Ficarra V, Righetti R, D'Amico A, et al. General state of health and psychological well-being in patients after surgery for urological malignant neoplasms. Urol Int 2000;65:130-4.

23. Yu C, Hequn C, Longfei L, et al. Sexual Function after Partial Penectomy: A Pro-spectively Study From China. Sci Rep 2016;6:21862.

24. Sosnowski R, Kulpa M, Kosowicz M, et al. Quality of life in penile carcinoma patients - post-total penectomy. Cent European J Urol 2016;69:204-11.

25. Dräger DL, Milerski S, Sievert KD, et al. [Psychosocial effects in patients with penile cancer: A systematic review]. Urologe A 2018;57:444-52.

26. Yang J, Chen J, Wu XF, et al. Glans preservation contributes to postoperative resto-ration of male sexual function: a multicenter clinical study of glans preserving surgery. J Urol 2014;192:1410-7.

27. Sedigh O, Falcone M, Ceruti C, et al. Sexual function after surgical treatment for penile cancer: Which organsparing approach gives the best results? Can Urol Assoc J 2015;9:E423-7.

28. Azrif M, Logue JP, Swindell R, et al. External-beam radiotherapy in T1-2 N0 penile carcinoma. Clin Oncol ( $\mathrm{R}$ Coll Radiol) 2006;18:320-5.

29. Parnham AS, Albersen M, Sahdev V, et al. Glansectomy and Split-thickness Skin Graft for Penile Cancer. Eur Urol 2018;73:284-9.

30. Lont AP, Gallee MP, Meinhardt W, et al. Penis conserving treatment for T1 and T2 penile carcinoma: clinical implications of a local recurrence. J Urol 2006;176:575-80; discussion 580 .

31. Blandy JP, Singh M, Notley RG, et al. The results and complications of scrotal-flap urethroplasty for stricture. $\mathrm{Br}$ J Urol 1971;43:52-7.

32. Shindel AW, Mann MW, Lev RY, et al. Mohs micrographic surgery for penile cancer: management and long-term followup. J Urol 2007;178:1980-5.

33. Mohs FE, Snow SN, Larson PO. Mohs micrographic surgery for penile tumors. Urol Clin North Am 1992;19:291-304.

34. Brown MD, Zachary CB, Grekin RC, et al. Penile tumors: their management by Mohs micrographic surgery. J Dermatol Surg Oncol 1987;13:1163-7. 
35. Machan M, Brodland D, Zitelli J. Penile Squamous Cell Carcinoma: Penis-Preserving Treatment With Mohs Micrographic Surgery. Dermatol Surg 2016;42:936-44.

36. Li J, Zhu Y, Zhang SL, et al. Organ-sparing surgery for penile cancer: complications and outcomes. Urology 2011;78:1121-4.

37. Burnett AL. Penile preserving and reconstructive surgery in the management of penile cancer. Nat Rev Urol 2016;13:249-57.

38. Tang DH, Yan S, Ottenhof SR, et al. Laser ablation as monotherapy for penile squamous cell carcinoma: A multicenter cohort analysis. Urol Oncol 2018;36:147-52.

39. Windahl T, Andersson SO. Combined laser treatment for penile carcinoma: results after long-term followup. J Urol 2003;169:2118-21.

40. Bandieramonte G, Colecchia M, Mariani L, et al. Peniscopically controlled CO2 laser excision for conservative treatment of in situ and $\mathrm{T} 1$ penile carcinoma: report on 224 patients. Eur Urol 2008;54:875-82.

41. Frimberger D, Hungerhuber E, Zaak D, et al. Penile carcinoma. Is Nd:YAG laser therapy radical enough? J Urol 2002;168:2418-21; discussion 2421.

42. Schlenker B, Tilki D, Seitz M, et al. Organ-preserving neodymi-um-yttrium-aluminium-garnet laser therapy for penile carcinoma: a long-term follow-up. BJU Int 2010;106:786-90.

43. Colecchia M, Nicolai N, Secchi P, et al. pT1 penile squamous cell carcinoma: a clini-copathologic study of 56 cases treated by CO2 laser therapy. Anal Quant Cytol Histol 2009;31:153-60.

44. Piva L, Nicolai N, Di Palo A, et al. [Therapeutic alternatives in the treatment of class T1N0 squamous cell carcinoma of the penis: indications and limitations]. Arch Ital Urol Androl 1996;68:157-61.

45. O'Kelly F, Lonergan P, Lundon D, et al. A Prospective Study of Total Glans Resur-facing for Localized Penile Cancer to Maximize Oncologic and Functional Outcomes in a Tertiary Referral Network. J Urol 2017;197:1258-63.

46. Hadway P, Corbishley CM, Watkin NA. Total glans resurfacing for premalignant le-sions of the penis: initial outcome data. BJU Int 2006;98:532-6.

47. Depasquale I, Park AJ, Bracka A. The treatment of balanitis xerotica obliterans. BJU Int 2000;86:459-65.

48. Shabbir M, Muneer A, Kalsi J, et al. Glans resurfacing for the treatment of carcinoma in situ of the penis: surgical technique and outcomes. Eur Urol 2011;59:142-7.

49. Malone PR, Thomas JS, Blick C. A tie-over dressing for graft application in distal penectomy and glans resurfacing: the TODGA technique. BJU Int 2011;107:836-40.

50. Palminteri E, Berdondini E, Lazzeri M, et al. Resurfacing and reconstruction of the glans penis. Eur Urol 2007;52:893-8.

51. Bracka A. Glans resection and plastic repair. BJU Int 2010;105:136-44.

52. Albersen M, Parnham A, Joniau S, et al. Predictive factors for local recurrence after glansectomy and neoglans reconstruction for penile squamous cell carcinoma. Urol Oncol 2018;36:141-6.

53. Pietrzak P, Corbishley C, Watkin N. Organ-sparing surgery for invasive penile cancer: early follow-up data. BJU Int 2004;94:1253-7.

54. O'Kane HF, Pahuja A, Ho KJ, et al. Outcome of glansectomy and skin grafting in the management of penile cancer. Adv Urol 2011;2011:240824.

55. Austoni E, Guarneri A, Colombo F, et al. Reconstructive surgery for penile cancer with preservation of sexual function. European Urology Supplements 2008;7:116.

56. Sansalone S, Garaffa G, Vespasiani G, et al. Glans reconstruction with the use of an inverted urethral flap after distal penile amputation for carcinoma. Arch Ital Urol Androl 2013;85:24-7.

57. Loughlin KR. Surgical management of penile carcinoma: the primary lesion. BJU Int 2006;97:655-67.

58. Korets R, Koppie TM, Snyder ME, et al. Partial penectomy for patients with squamous cell carcinoma of the penis: the Memorial Sloan-Kettering experience. Ann Surg Oncol 2007;14:3614-9.

59. Guimarães GC, Cunha IW, Soares FA, et al. Penile squamous cell carcinoma clinico-pathological features, nodal metastasis and outcome in 333 cases. J Urol 2009;182:528-34; discussion 534.

60. Mistry T, Jones RW, Dannatt E, et al. A 10-year retrospective audit of penile cancer management in the UK. BJU Int 2007;100:1277-81.

61. Ozsahin M, Jichlinski P, Weber DC, et al. Treatment of penile carcinoma: to cut or not to cut? Int J Radiat Oncol Biol Phys 2006;66:674-9.

62. Ceilley RI. Mechanisms of action of topical 5-fluorouracil: review and implications for the treatment of dermatological disorders. J Dermatolog Treat 2012;23:83-9.

63. Manjunath A, Brenton T, Wylie S, et al. Topical Therapy for non-invasive penile cancer (Tis)-updated results and toxicity. Transl Androl Urol 2017;6:803-8.

64. Schön MP, Schon M. Imiquimod: mode of action. Br J Dermatol 2007;157 Suppl 2:8-13.

65. Lucky M, Murthy KV, Rogers B, et al. The treatment of 
penile carcinoma in situ (CIS) within a UK supra-regional network. BJU Int 2015;115:595-8.

66. Deen K, Burdon-Jones D. Imiquimod in the treatment of penile intraepithelial neo-plasia: An update. Australas J Dermatol 2017;58:86-92.

67. Alnajjar HM, Lam W, Bolgeri M, et al. Treatment of carcinoma in situ of the glans penis with topical chemotherapy agents. Eur Urol 2012;62:923-8.

68. Crook J, Ma C, Grimard L. Radiation therapy in the management of the primary penile tumor: an update. World J Urol 2009;27:189-96.

69. Raskin Y, Vanthoor J, Milenkovic U, et al. Organ-sparing surgical and nonsurgical modalities in primary penile cancer treatment. Curr Opin Urol 2019;29:156-64.

70. Burt LM, Shrieve DC, Tward JD. Stage presentation, care patterns, and treatment outcomes for squamous cell carcinoma of the penis. Int J Radiat Oncol Biol Phys 2014;88:94-100.

71. Zouhair A, Coucke PA, Jeanneret W, et al. Radiation therapy alone or combined surgery and radiation therapy in squamous-cell carcinoma of the penis? Eur J Cancer 2001;37:198-203.

72. Cordoba A, Escande A, Lopez S, et al. Low-dose brachytherapy for early stage penile cancer: a 20-year single-institution study (73 patients). Radiat Oncol

Cite this article as: Yao HH, Sengupta S, Chee J. Penile sparing therapy for penile cancer. Transl Androl Urol 2020;9(6):3195-3209. doi: 10.21037/tau.2019.08.07
2016;11:96.

73. Delaunay B, Soh PN, Delannes M, et al. Brachytherapy for penile cancer: efficacy and impact on sexual function. Brachytherapy 2014;13:380-7.

74. Cordoba A, Escande A, Lopez S, et al. Erratum to: Lowdose brachytherapy for early stage penile cancer: a 20year single-institution study (73 patients). Radiat Oncol 2016;11:129.

75. de Crevoisier R, Slimane K, Sanfilippo N, et al. Longterm results of brachytherapy for carcinoma of the penis confined to the glans (N- or NX). Int J Radiat Oncol Biol Phys 2009;74:1150-6.

76. Gotsadze D, Matveev B, Zak B, et al. Is conservative organ-sparing treatment of penile carcinoma justified? Eur Urol 2000;38:306-12.

77. Crook JM, Jezioranski J, Grimard L, et al. Penile brachytherapy: results for 49 patients. Int J Radiat Oncol Biol Phys 2005;62:460-7.

78. Rozan R, Albuisson E, Giraud B, et al. Interstitial brachytherapy for penile carcinoma: a multicentric survey (259 patients). Radiother Oncol 1995;36:83-93.

79. Opjordsmoen S, Waehre H, Aass N, et al. Sexuality in patients treated for penile cancer: patients' experience and doctors' judgement. Br J Urol 1994;73:554-60. 